\title{
Correction to: Implicit Beliefs about Teaching Ability, Teacher Emotions, and Teaching Satisfaction
}

\author{
Ma. Jenina N. Nalipay ${ }^{1} \cdot$ Imelu G. Mordeno ${ }^{2} \cdot$ J-roel B. Semilla $^{2} \cdot$ Cherry E. Frondozo $^{1}$
}

Published online: 22 August 2019

(C) De La Salle University 2019

Correction to: Asia-Pacific Edu Res (2019) 28(4):313-325
https://doi.org/10.1007/s40299-019-00467-z

In the original publication of the article, some of the values in Fig. 1 were published incorrectly; thus, the following corrections were made:

Path between incremental and learning was changed from 1.00 to 1.03 .
Path between incremental and enjoyment was changed from -0.71 to 0.71 .

Residual for satisfaction was changed from 10.46 to 10.26 .

The correct version is provided in this correction (Fig. 1).

The original article can be found online at https://doi.org/10.1007/s40299-019-00467-z.

\section{Ma. Jenina N. Nalipay}

jmjnalipay@eduhk.hk

1 Department of Curriculum and Instruction, Education University of Hong Kong, 10 Lo Ping Rd, Ting Kok, Tai Po, New Territories, Hong Kong, SAR, China

2 Mindanao State University - Iligan Institute of Technology, Iligan City, Philippines 


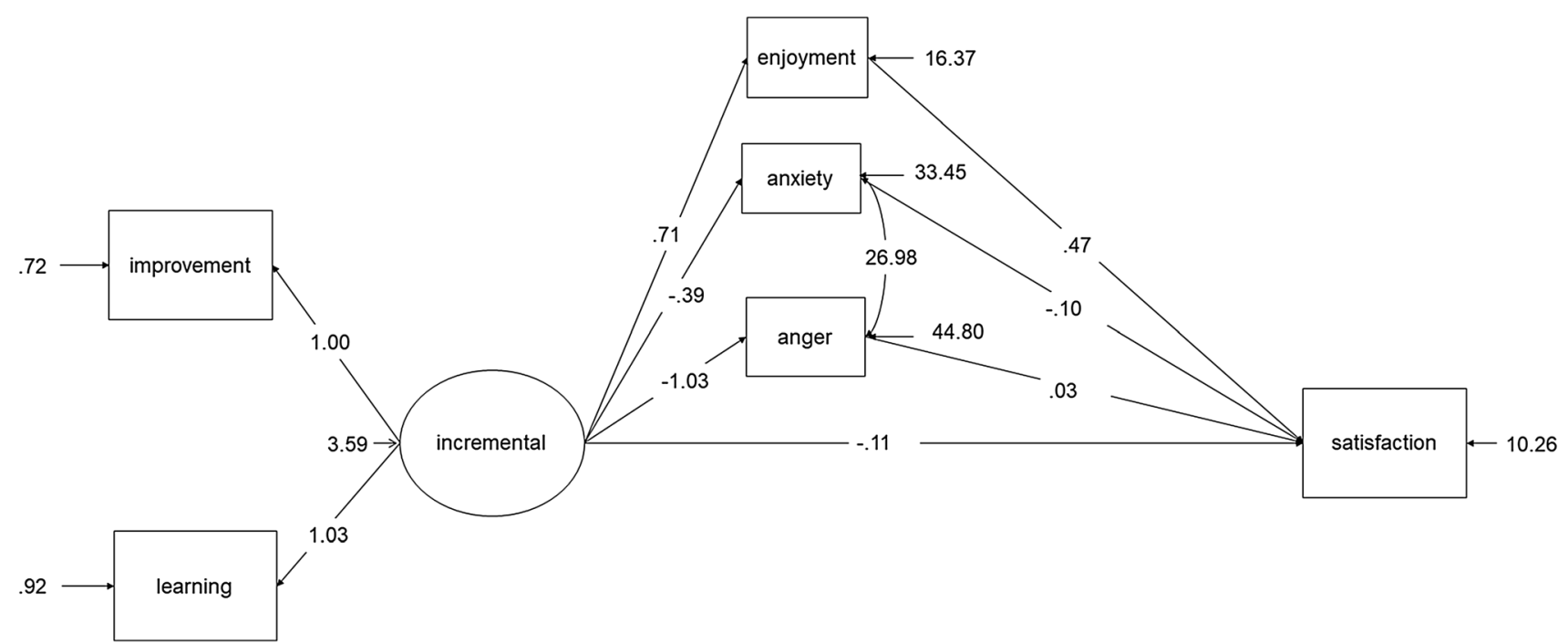

Fig. 1 Indirect effect of incremental beliefs about teaching ability on teaching satisfaction through teacher emotions (model 1A). Note all coefficients are unstandardized

Publisher's Note Springer Nature remains neutral with regard to jurisdictional claims in published maps and institutional affiliations. 